Methodology We are reporting three different cases with choriocarcinoma with different presentations whether postmenopausal presentation, isthmic lesions, and later presentation after hysterectomy with vaginal metastasis.

Result(s)* All cases were managed surgically with reporting of their management in detail.

Conclusion* The majority of choriocarcinoma cases are intrauterine and of gestational origin. postmenopausal and cervical choriocarcinoma are rare presentations of this pathology. It is important to include cervical choriocarcinoma in the differential diagnosis of cervical lesions during the reproductive age despite the extremely low incidence as an ectopic entity. Choriocarcinoma is completely curable by chemotherapy even in the presence of metastasis. If massive life-threatening vaginal bleeding occurs, surgery is needed. We should consider vaginal metastasis in any vaginal mass after hysterectomy for a suspected tumor as a vesicular mole or endometrial cancer.

\section{PARTIAL HYDATIDIFORM MOLE WITH A LIVING FETUS: A NEED FOR A MANAGEMENT GUIDELINE.-}

${ }^{1}$ RAEA Hemida*, ${ }^{2} \mathrm{~K}$ Zalata. ${ }^{1}$ Faculty of Medicine - Mansoura University , Obstetrics and Gynecology, Mansoura, Egypt; ${ }^{2}$ Faculty of Medicine - Mansoura University كلية الطب جامعة المنصورة, Pathology, Mansoura, Egypt

\subsection{6/ijgc-2021-ESG0.612}

Introduction/Background* Partial mole (PM) results from dispermic fertilization of a normal oocyte and produces a triploid set of chromosomes and is commonly associated with the presence of congenital fetal malformations. Partial molar pregnancy with an existing live fetus is a very rare condition, occurring in 0.005 to $0.01 \%$ of all pregnancies. It is sometimes called "Sad Fetus Syndrome". It presents a challenging diagnosis, especially when clinical signs are almost completely absent and a challenging management when the patient is interested to continue her pregnancy. Currently, there is no international guidelines for management.

Methodology A retrospective analysis of the patients presented with partial mole with a living fetus to our GTD clinic, Mansoura University, Egypt in the last 5 years. Clinical characteristics and outcome were described. An Excel sheet and SPSS program were used for statistical analysis.

Result(s)* From September 2015 to August, 2020; eleven cases of PM with living fetus were managed in our hospital. Mean age was 25.7 years while mean parity was 1.2. Amniocentesis was performed in one case and was normal. Duration of pregnancy ranged from 14 to 37 weeks. The fetal outcome was normal preterm fetus in two cases (18.2\%), infantile death after 2 months because of congenital fetal malformations in one case, early neonatal death because of severe prematurity in two cases, and induction of abortion or hysterotomy because of complications in 6 cases.

Maternal complications occurred in 6 cases (54.5\%); hemorrhage in 4 cases $(36.4 \%)$, pre-eclampsia-eclampsia in two cases $(18.2 \%)$, hyperemesis gravidarum in one case $(9.1 \%)$, and postmolar gestational trophoblastic neoplasia (GTN) in one case $(9.1 \%)$.
Moreover, three cases (27.3\%) presents as familial recurrent hydatidiform mole with proved NLRP7 gene mutation in two. Conclusion* Maternal and fetal outcome of partial molar pregnancy with a living fetus is poor. Counseling of the patients for termination of pregnancy may be need. A global guideline for management is required.

\section{Vaginal and vulvar cancer}

\section{EPIDEMIOLOGY OF VAGINAL MALIGNANT LESIONS IN THE REPUBLIC OF BELARUS}

${ }^{1}$ OP Matylevich*, 'V Petukhov, 'S Mavrichev, ${ }^{2} \mathrm{O}$ Zubets. 'NN Alexandrov National Cancer Centre of Belarus, Gynecologic Oncology Department, Minsk, Belarus; ${ }^{2} N N$ Alexandrov National Cancer Centre of Belarus, Cancer Control Department, Minsk, Belarus

\subsection{6/ijgc-2021-ESG0.613}

Introduction/Background* Vaginal malignant lesions (VML) are a rather rare pathology and account for only $1-2 \%$ of all cases of cancer of the female reproductive system. In Belarus, over a 20-year period (2000-2019), 690 cases of VML (C52) were registered. The aim of the study was to estimate incidence, mortality and survival rate of newly diagnosed VML in Belarus from 2000 to 2019.

Methodology The data from the Belarusian Cancer Registry were analyzed.

Result(s)* The estimated age-standardized incidence rate of VML per 100,000 female population in Belarus has increased from 0.2 in 2000 to 0.4 in 2019 ( $p>0.05$ ). The mortality rate for 20 years was at the same level and amounted to 00.2 per 100,000 female population.

Of all newly diagnosed cases of VML over 20 years, $71.9 \%$ (496) were residents of the city and $28.1 \%$ (194) were rural residents.

The analysis of the age distribution showed two peaks of morbidity in the age categories 50-54 and 70-74 years, and these peaks are observed in all five-year periods.

Comparison of two ten-year periods (2000-2009 and 20102019) showed that rate of stage I increased by $11 \%$ (from $28.3 \%$ to $39.3 \%$ ), as rate of stages II and III decreased by $7.2 \%$ (from $42.4 \%$ to $35.2 \%$ ) and $5.4 \%$ (from $16.8 \%$ to $11.4 \%$ ), respectively, and no change for stage IV (from 10.0\% to $11.4 \%)$.

Comparison of 5 -year adjusted survival rates between 2000 and 2019 showed increased by $9.7 \%$ for stage I $(71.0 \%$ $\pm 20.9 \%$ and $77.9 \% \pm 9.8 \%$, respectively), increased almost doubled at stages II and III $(40.7 \% \pm 10.5 \%$ and $75.5 \%$ $\pm 6.5 \%, 32.0 \% \pm 9.8 \%$ and $53.9 \% \pm 18.0 \%$, respectively), and stage IV patients do not survive the 5 -year mark.

Conclusion* In Belarus, for 20 years, morbidity and mortality of VMN remain stable. The quality of diagnostics has improved due to an increase in incidence of stage $I$ and a decrease of stages II and III, as well as improved approaches to treatment, which is confirmed by data on an increase in survival. 